\title{
Retinal Venous Occlusions: Diagnosis and Choice of Treatments
}

\author{
Giuseppe Querques $^{\mathrm{a}}{ }^{\mathrm{b}} \quad$ Giacinto Triolo $^{\mathrm{b}} \quad$ Giuseppe Casalino $^{\mathrm{b}}$ \\ José García-Arumíc Josep Badalc Miguel Zapatac Ana Boixaderac \\ Vicente Martinez Castilloc ${ }^{c}$ Francesco Bandello ${ }^{b}$ \\ a Department of Ophthalmology, University Paris-Est Créteil, Centre Hospitalier Intercommunal de Créteil,

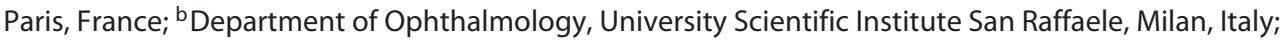 \\ 'Instituto de Microcirurgia Ocular and Department of Ophthalmology, Hospital Vall Hebron, Barcelona, Spain
}

\section{Key Words}

Branch retinal vein occlusion . Central retinal vein

occlusion - Macular edema - Treatment options

\begin{abstract}
Retinal vascular occlusive disorders constitute one of the major causes of blindness and impaired vision. There is marked controversy on their pathogeneses, clinical features and particularly their management. Recently, advances in clinical research added antivascular endothelial growth factor, corticosteroids and sustained-release implants to our armamentarium in the management of retinal vein occlusions. The purpose of our paper is to provide an update and a brief review on the current treatment options of retinal vein occlusions.

Copyright $\odot 2013$ S. Karger AG, Basel
\end{abstract}

\section{Introduction}

Retinal vein occlusions (RVOs) are the second most common blinding vascular retinal disorder after diabetic retinopathy $[1,2]$. Two main types of RVO exist: (i) branch RVO (BRVO), when the occlusion involves one temporal or nasal branch of the central retinal vein exclusively, and (ii) central RVO (CRVO), when the occlusion involves the whole central retinal vein. The most common vision-threatening complications are retinal ischemia and macular edema [3].

In the last years, new treatment modalities have been suggested for macular edema, including intravitreal antivascular endothelial growth factor (VEGF) agents and corticosteroids. These molecules have led to substantial changes in the management of RVO-associated macular edema $[3,4]$. The purpose of our paper is to provide an update and a brief review on the current treatment options for RVOs.

\section{Central Retinal Vein Occlusion}

Although the main known risk factors of CRVO are hypertension and open-angle glaucoma [5-8], the pathogenesis is yet not well understood. It is thought to be a compartment syndrome, since in a 1.5 -mm-diameter area, the central retinal artery, the central retinal vein and the optic nerve coexist. Thrombotic occlusion is thought to develop as the result of an increase in the arterial diameter, changes in the scleral ring and the presence of ana-

\section{KARGER}

E-Mail karger@karger.com

www.karger.com/ore
(C) 2013 S. Karger AG, Base

0030-3747/13/0494-0215\$38.00/0
Dr. Giuseppe Querques

Department of Ophthalmology, University Paris-Est Créteil

Centre Hospitalier Intercommunal de Créteil

40 Avenue de Verdun, FR-94000 Créteil (France)

E-Mail giuseppe.querques@ hotmail.it 
tomical anomalies and possible systemic factors, which together cause a decrease in the venous lumen, increased turbulence, damage to endothelium and thrombus formation. This is supported by histological studies that localize the thrombus in the lamina cribrosa in most or all cases $[9,10]$.

It is clear from the Central Vein Occlusion Study [11] that, in the natural course of the disease, the vision in patients with CRVO will most likely worsen or remain unchanged and that those patients with poor vision initially have little hope of significant spontaneous recovery. $\mathrm{Nu}$ merous treatments are available, including panretinal laser photocoagulation, grid macular laser photocoagulation, chorioretinal anastomosis (CRA) via high-intensity laser photocoagulation, and intraocular injections of drugs, with varying degrees of effectiveness and complication rates. One surgical procedure that has been developed is termed radial optic neurotomy (RON). Panretinal laser photocoagulation has only been effective in managing neovascular complications, and grid macular laser photocoagulation only decreases macular edema without increasing the final visual acuity $[1,11,12]$.

\section{Pharmacological Treatment}

Recombinant Tissue Plasminogen Activator

Thrombolytic agents have been proposed as a treatment against a suspected thrombus in the central retinal vein. Recombinant tissue plasminogen activator (rtPA) is a synthetic fibrinolytic agent that converts plasminogen to plasmin and destabilizes intravascular thrombi. rtPA, as therapy against CRVO, has been administered by several routes: systemic [13,14], intravitreal [15-17], and by endovascular cannulation of retinal vessels either through a neuroradiological or a vitreoretinal approach, and delivery of minute quantities of rtPA directly to the occluded vessels to release the suspected thrombus $[18,20,21]$.

\section{Intraocular Corticosteroids}

The exact mechanism of action of corticosteroids in modulating retinal edema is unknown, but it is believed that a combination of anti-inflammatory effects with modulation of cytokine and growth factor production and stabilization of the blood-retinal barrier with reduction in vascular permeability may be involved. Several reports from intravitreal triamcinolone for CRVO macular edema have been published [22], showing initial improvement but with no longer benefit after a 1-year period. High incidences of cataract (63\%) and glaucoma (30\%) have also been reported as complications from intravitreal triamcinolone.
The first multicenter, randomized clinical trial in this area is the SCORE study, which compared the efficacy and safety of 1- and 4-mg doses of preservative-free intravitreal triamcinolone with observation in eyes with vision loss associated with macular edema secondary to perfused CRVO. Retreatment was done if necessary every 4 months. The SCORE study report 10 [23] showed the results in terms of changes in best-corrected visual acuity (BCVA) and central macular thickness, about 238 and 151 patients at month 12 and 24, respectively. In general, more eyes had a loss $\geq 15$ in BCVA letter score ( 31 and $34 \%)$ than a gain (20 and 23\%) at month 12 and 24, respectively, with a mean loss in visual acuity letter score of approximately 5 at both time points. CRVO eyes had decreasing OCT-measured center-point thickness over follow-up, with 38 and $47 \%$ of CRVO eyes $\leq 250 \mu \mathrm{m}$ at month 12 and 24, respectively. The SCORE study report 5 [24] demonstrated that more eyes in the 4-mg triamcinolone group (35\%) initiated intraocular pressure (IOP)-lowering medication through 12 months compared with the $1-\mathrm{mg}$ triamcinolone $(20 \%)$ and observation groups (8\%). Among eyes that were phakic at baseline, the estimate through month 12 of new-onset lens opacity or progression of an existing opacity in the observation group was $18 \%$ compared with 26 and $33 \%$ for the 1- and 4-mg triamcinolone groups, respectively.

Dexamethasone is a potent, water-soluble corticosteroid that can be delivered to the vitreous cavity by the dexamethasone intravitreal implant (DEX implant; OZURDEX, Allergan, Inc.). A DEX implant is composed of a biodegradable copolymer of lactic acid and glycolic acid containing micronized dexamethasone. The drugcopolymer complex gradually releases the total dose of dexamethasone over a series of months after insertion into the eye through a small 22-gauge pars plana puncture using a customized applicator system.

In a 12-month, prospective, multicenter, phase III clinical trial, the GENEVA study $[25,26]$, a total of 1,256 patients affected by RVOs received a first injection with either DEX implant ( 0.7 or $0.35 \mathrm{mg}$ ) or sham at baseline, and a second injection with DEX implant $0.7 \mathrm{mg}$ at month 6 if the study's criteria for retreatment were respected [BCVA $<84$ letters $(20 / 20)$ or central retinal thickness $(\mathrm{CRT})>250 \mu \mathrm{m}]$. The results showed that injection and reinjection with DEX implant $0.7 \mathrm{mg}$ in patients who met retreatment criteria was safe and well tolerated over 12 months. The improvements in BCVA and CRT after a second treatment with DEX implant $0.7 \mathrm{mg}$, as well as the safety profile, were similar to those seen after the first treatment, except that more cataract progression oc- 
curred in eyes that received retreatment with $0.7-\mathrm{mg}$ DEX implant. Steroid-induced increases in IOP after each DEX implant treatment were predictable and typically were controlled with topical IOP-lowering medication. In the 327 patients who were treated initially with sham injection and did not receive a first DEX implant until the first 6 months, the mean improvement in BCVA did not seem to be as robust as that seen in patients who received their first DEX implant 6 months earlier in the study, perhaps suggesting that delaying treatment in eyes with macular edema owing to RVO may decrease the ability of patients to benefit from treatment.

Several additional modes of delivery are being evaluated in the preclinical and clinical trial setting to determine safety and efficacy. The Iluvien sustained-release fluocinolone acetonide device (Alimera Sciences) is an injectable, nonbiodegradable, intravitreal insert designed for sustained release of the corticosteroid fluocinolone acetonide for up to 36 months. The drug is injected through a 25 -gauge inserter needle. There are two intravitreal triamcinolone acetonide implants under study: the I-vation (SurModics, Inc.) and the Verisome delivery system (Icon Biosciences, Inc.). The Cortiject implant (NOVA63035; Novagali Parma) is a preservative and solvent-free emulsion that contains a tissue-activated proprietary corticosteroid prodrug that is activated at the level of the retina once released. For several years, repeated intravitreal injections of non-FDA-approved triamcinolone acetonide have been used for this disease. These new sustained-release delivery systems may provide better side-effect profiles and reduce the need for repeated intravitreal injections.

\section{Anti-VEGF Drugs}

Following CRVO, subsequent hypoxia leads to upregulation of VEGF, resulting in increased retinal capillary permeability and leakage of fluid and blood into the intraretinal space. In addition, VEGF is a key promoter of angiogenesis, potentially contributing to the development of neovascularization associated with CRVO. Antiangiogenic drugs may decrease vascular permeability and macular edema. Bevacizumab has been the most studied drug in this disease. Good safety and effectiveness in the short term have been reported with this drug. The main limitations of this treatment modality are its short-term effectiveness and high recurrence rate [27-29].

Ranibizumab is a humanized, affinity-matured antiVEGF antibody fragment that binds to and neutralizes all isoforms of VEGF-A and their biologically active degradation products. It is the other drug studied for CRVO.
In a 12 -month, phase III, multicenter randomized trial, the CRUISE study [30], which included a 6-month, injection-controlled treatment period followed by a 6-month observation period, 392 participants were evaluated in 3 groups ( $0.3 \mathrm{mg}, 0.5 \mathrm{mg}$ or sham injection every month). The percentage of patients who had an improvement from baseline BCVA letter score of $\geq 15$ at month 6 time point was $46.2,47.7$ and $16.9 \%$, respectively. This gain was maintained in the ranibizumab groups up to 12 months [31]. The percentage increased up to $33.1 \%$ at month 12 in the group of patients treated with sham injection at baseline, who received a $0.5-\mathrm{mg}$ ranibizumab injection given as needed throughout the observation period. At month 6, the mean change from baseline central foveal thickness (CFT) was a reduction of 433.7 and 452.3 $\mu \mathrm{m}$ in the 0.3 - and 0.5 - $\mathrm{mg}$ ranibizumab groups, respectively, compared with a reduction of $167.7 \mu \mathrm{m}$ in the sham group. In the 0.3- and 0.5-mg treatment groups, these reductions were maintained with as-needed ranibizumab during the observation period.

In an open-label, single-arm, multicenter extension trial, the HORIZON study [32], 304 patients who completed CRUISE were evaluated at least every 3 months and treated with ranibizumab injections given as needed. Data were available for 181 patients at 12 months. From CRUISE baseline, at month 12 of HORIZON: (i) the percentage of patients who had an improvement of $\geq 15$ letters was $38.3-45.1 \%$ in the different groups and (ii) the mean CFT reduction was 370.9-418.7 $\mu \mathrm{m}$. However, from HORIZON baseline, mean CFT increased by 68.4$88.3 \mu \mathrm{m}$ at month 12 . This study concluded that the reduced frequency of ranibizumab injections in the second year was observed in conjunction with worsening of outcome measures in CRVO patients. Many patients with CRVO who had substantial gains during 1 year of intensive ranibizumab treatment were not stabilized and required further ranibizumab treatment.

VEGF Trap-Eye (aflibercept injection; Regeneron Pharmaceuticals) is a $115-\mathrm{kDa}$ decoy receptor fusion protein comprising the second domain of human VEGF receptor 1 and the third domain of VEGF receptor 2 fused to the Fc domain of human immunoglobulin G1 [33]. Its binding affinity for VEGF is substantially greater than that of either bevacizumab or ranibizumab [34]. It could have a substantially longer duration of action in the eye [35], allowing for less frequent administration, as supported by early clinical trials [36]. In a phase III, prospective, randomized double-masked study, the COPERNICUS study [37], 189 eyes with macular edema secondary to CRVO were randomized 3:2 to receive VEGF Trap-Eye 
( $2 \mathrm{mg}$ ) or sham injection monthly for 6 months. At week $24,56.1 \%$ of VEGF Trap-Eye-treated eyes gained $\geq 15$ letters from baseline versus $12.3 \%$ of sham-treated eyes. CRT decreased by $457.2 \mu \mathrm{m}$ in eyes treated with VEGF Trap-Eye versus $144.8 \mu \mathrm{m}$ in sham-treated eyes.

In the GALILEO study [38], 177 patients were randomized to either intravitreal injections of aflibercept ( $2 \mathrm{mg}$ every month) or sham injections. From week 24 to 52, patients in the aflibercept group were treated on a pro re nata basis. At week $52,60.2 \%$ of patients in the aflibercept group gained $\geq 15$ letters from baseline, compared with $32.4 \%$ of patients in the placebo group. Patients receiving aflibercept experienced a significantly larger mean decrease in CRT than patients receiving placebo $(-423.5 \mu \mathrm{m}$ vs. $-219.3 \mu \mathrm{m})$.

In a dose-ranging, double-masked, multicenter phase II trial, subjects with CRVO for 6 months or less duration were randomly assigned to receive pegaptanib sodium $(0.3$ and $1 \mathrm{mg}$ ) or sham injections every 6 weeks for 24 weeks. Results at week 30 showed that $36 \%$ of subjects treated with $0.3 \mathrm{mg}$ of pegaptanib sodium and $39 \%$ treated with $1 \mathrm{mg}$ gained $\geq 15$ letters from baseline versus $28 \%$ sham-treated subjects [39]. The main problem with these drugs arises from the question of what will happen when injections are stopped. In a recent review from the Cochrane database, the authors conclude that ranibizumab and pegaptanib sodium have shown promise in the shortterm treatment of nonischemic CRVO macular edema. However, effectiveness and safety data from larger randomized clinical trials with follow-up beyond 6 months are not yet available. There are no randomized clinical trial data on anti-VEGF agents in ischemic CRVO macular edema. The use of anti-VEGF agents to treat this condition, therefore, remains experimental [40].

\section{Pars Plana Vitrectomy}

Pars plana vitrectomy (PPV) techniques are used to address complications of central vein occlusion and, in investigational studies, to attempt to alter the natural course of the disease. Eyes with nonclearing vitreous hemorrhage from secondary retinal neovascularization may require surgical evacuation. At the time of vitrectomy, clearing of the hemorrhage can be combined with removal of epiretinal membranes and removal of fibrovascular proliferations, if present, and the placement of complete endolaser panretinal laser photocoagulation [41]. Although this technique may prevent or aid in regression of anterior segment neovascularization, visual outcomes may be limited due to the extent of underlying retinal nonperfusion [42]. In order to improve oxygen- ation of the fovea and fluid exchange with the vitreous cavity, some authors suggest peeling the internal limiting membrane (ILM) [43].

\section{Radial Optic Neurotomy}

RON consists of a transvitreal incision of the nasal scleral ring in order to release pressure on the central retinal vein at the level of the scleral outlet [44]. It is performed by PPV followed by use of a 25-gauge microvitreoretinal blade to incise the lamina cribrosa and adjacent retina. In the initial retrospective report of 11 eyes by Opremcak et al. [44], successful RON was performed with no complications. There was clinical improvement in retinal hemorrhages and venous congestion. García-Arumí et al. [45] reported, in a prospective interventional trial, successful RON surgery in 14 eyes. Overall, 57\% gained 1 line of distance visual acuity, and visual recovery was significantly related to reduction in macular edema. Six (43\%) developed a postoperative CRA at the RON site with a trend towards better final acuity compared to those without anastomosis formation (20/60 vs. 20/110). The CRA seen at RON sites may allow for more active drainage of retinal edema and hemorrhage compared to laser-induced CRA. When evaluating the effectiveness of RON for CRVO in patients $<50$ years of age versus those $>50$ in 43 patients [46], better functional results were observed in younger patients ( 50 vs. $30 \%$ gained 15 letters), although functional improvement remained limited in those with low baseline visual acuity. In 2006, Opremcak et al. [47] reported on 117 patients with CRVO and severe loss of vision $(\leq 20 / 200)$ treated with PPV and RON. Visual acuity improved in $71 \%$ of patients, with an average of 2.5 lines of vision gained.

Finally, in a prospective, 12 -month, randomized multicenter trial, the ROVO study [48], 83 patients with CRVO were treated with either RON, a single intravitreal injection of $4 \mathrm{mg}$ triamcinolone acetonide, or a placebo treatment. One year after RON, the percentage of patients who showed an improvement $>3$ lines logMAR of visual acuity was 47,20 and $10 \%$ of patients treated with RON, IVT injection and placebo, respectively. There was no significant decrease in retinal thickness at 12 months after any of the three treatment options.

\section{Branch Retinal Vein Occlusion}

BRVO most commonly occurs at an arteriovenous crossing $[49,50]$. Systemic hypertension, diabetes mellitus, and history of cardiovascular disease are the most 
common risk factors associated with BRVO [51, 52]. Histopathological studies showed that changes in rigidity of the artery associated to hypertension induce a vein compression producing turbulence, endothelial cell damage and thrombus formation [53].

The BRVO study demonstrated that grid photocoagulation improves macular edema and vision in patients with macular edema secondary to BRVO but with preserved foveal vascularization [54]; this improvement was slight, only 1.3 ETDRS lines at 3 years.

Macular edema is the main cause of decrease in visual acuity in BRVO. The approaches to the management of $B R V O$ are addressed to reperfuse the thrombosed vein, to reduce the permeability of the macular vascular net improving the edema, and to increase the vitreoretinal fluid exchange of oxygen and protecting factors.

\section{Pharmacological Treatment}

Recombinant Tissue Plasminogen Activator

Potential benefits of plasminogen activator include the thrombus resolution. Intravitreal tissue plasminogen activator has been used alone [55] and in combination with sheathotomy [56] for BRVO. Results are encouraging, but actually there are no comparative studies with other treatments.

\section{Intraocular Corticosteroids}

The exact mechanism of macular edema development from BRVO has not been elucidated, but breakdown of the blood-retinal barrier is thought to play a role. Potential roles of corticosteroids are the decrease in vascular permeability and the stabilization of this blood-retinal barrier.

The SCORE study [57] compared the efficacy and safety of 1- and 4-mg doses of preservative-free intravitreal triamcinolone with standard care (grid photocoagulation in eyes without dense macular hemorrhage and deferral of photocoagulation until hemorrhage clears in eyes with dense macular hemorrhage) for 411 patients with macular edema secondary to BRVO. Despite good initial results with triamcinolone, conclusions are that there is no difference in visual acuity at 12 months for the standard care group compared with the triamcinolone groups. The percentage of increase of IOP and lens opacity or progression of an existing cataract through month 12 was higher in the triamcinolone groups compared with the standard care group. At this point the use of intravitreal triamcinolone is not recommended in macular edema secondary to BRVO. Due to its antiedematous and antiangiogenic effects, intravitreal dexamethasone has been used in studies on RVOs [58].

Retinal Vein Occlusions
The GENEVA study $[25,26]$ reported that the time to achieve a $\geq 15$-letter improvement in BCVA was significantly less in both DEX implant groups ( 0.35 and $0.7 \mathrm{mg}$ ) compared with sham, after a single administration. Gain in visual acuity was set at days 30-90 but not significant at day 180. Moreover, mean BCVA slowly improved over the course of the study among BRVO eyes treated with sham. However, the initiation of treatment in the sham group did not achieve the same extent of visual gain as seen after the primary treatment [26]. Given that longer macula edema duration was associated with lower functional improvements after DEX implant, a recent study outlines how a prompt treatment may be associated with improved clinical outcomes [59]. Although the long-term safety profile of DEX implant has recently been reported [60], the optimal retreatment schedule has not yet been established.

\section{Anti-VEGF Drugs}

VEGF is elevated in the vitreous of patients with BRVO and plays an important role in the pathogenesis of macular edema [61]. Antiangiogenic drugs may decrease vascular permeability and also macular edema. Bevacizumab has been the most studied drug in this disease. We can find short series of cases and retrospective comparative studies concluding good safety and efficacy in the short term with this drug [62]. Large and prospective studies report that limitations of this treatment modality are its short-term effectiveness and high recurrence rate [63].

A prospective, randomized, phase III, double-masked, multicenter clinical trial evaluated the efficacy of ranibizumab for BRVO, including a 6-month injection-controlled period followed by a 6 -month observation period in which retreatment was given as needed (BCVA $<20 / 40$ or retinal thickness $>250 \mu \mathrm{m})[64,65]$.

The percentage of patients who gained $\geq 15$ letters in BCVA at month 6 was $55.2 \%(0.3 \mathrm{mg})$ and $61.1 \%(0.5 \mathrm{mg})$ in the ranibizumab groups and $28.8 \%$ in the sham group [64]. At month 12, treatment with ranibizumab maintained, on average, the benefits achieved by 6 monthly ranibizumab injections. In those patients who initially received sham injection, treatment with ranibizumab as needed for 6 months resulted in improvement in BCVA, but to a lesser extent than in the 2 ranibizumab groups [65]. In an open-label extension trial of the 12-month BRVO study, vision remained stable and no new safety events were identified with long-term use of ranibizumab [66].

Pegaptanib sodium studies suggest improvement of visual acuity at week 54 in both $0.3-$ and 1-mg doses [67].

Ophthalmic Res 2013;49:215-222 


\section{Pars Plana Vitrectomy}

There is evidence that PPV and posterior hyaloid dissection may increase oxygenation of the macula, and in some cases vitreomacular attachment itself may contribute to the development of macular edema [68]. Moreover, vitrectomy might play a part in the removal event of proinflammatory and proangiogenic factors and prevent hypoxia [69].

Despite the lack of large clinical trials, recently PPV has been shown to improve perifoveal microcirculation and the visual prognosis in BRVO patients with macular edema [70].

In order to improve oxygenation of the fovea and anatomical and functional outcomes of vitrectomy some authors proposed the peeling of the ILM [71]. A short series of cases have found good outcomes with this technique [72]. Arai et al. [73] did not find any difference in a nonrandomized, comparative study between PPV with and without ILM peeling for BRVO and concluded that there is no additional benefit in removing the ILM for BRVOassociated macular edema.

\section{Sheathotomy}

A few years after histological changes in BRVO were described in 1982 [53], Osterloh and Charles [74] published the first report of surgical decompression for BRVO. Given that venous narrowing at the crossing site is the main cause for BRVO, the rationale of surgery is the removal of the compressive factor by sectioning the adventitial sheath (sheathotomy) that the artery and vein share at crossing point. In 1998, Kumar et al. [75] described that sheathotomy may be an effective treatment for BRVO. Surgical technique consists of a PPV with posterior hyaloid dissection. Potential benefits of sheathotomy include the mechanical decompression of the venule and thrombus release. Successful decompressive surgery is usually followed by the disappearance of collateral vessels at the BRVO blockage site, which is a clinical marker for intravascular reperfusion, and resolution of hemorrhages and macular edema [76].
However, the usefulness of sheathotomy is still controversial. García-Arumí et al. [56] and Mester et al. [71] reported good visual results in patients treated with sheathotomy. Moreover, sheathotomy showed significantly better visual outcomes than a matched control group of observation and laser-treated eyes [77]. However, after 6 months of follow-up it resulted in similar functional and anatomical outcomes to intravitreal triamcinolone treatment [78]. Similarly, sheathotomy did not lead to a distinct functional benefit in a study that compared 2 groups of patients that underwent PPV with or without sheathotomy. At this point no randomized, controlled study evaluating the benefit of sheathotomy has been published.

\section{Conclusions}

As medical research progresses, the selection of options available for patients with RVOs widens and improves. The development of intravitreal pharmacotherapy has revolutionized the management of RVO, whose treatment options were previously limited. The main downsides are: for anti-VEGF drugs the need for repeated injections, and for corticosteroids the side effects of cataract and increased IOP. Moreover, there are no phase III clinical trials comparing the various pharmacological agents head to head. A combination of treatments may offer the best approach, but we still have lack of evidence.

In addition, sustained drug delivery to the posterior segment as a therapeutic option is increasing. Current experience suggests that the use of these devices will continue increasing over time. However, when treating macular edema secondary to RVO, we are still unable to address the primary mechanism of the disease: the vein occlusion.

Further research is warranted to better understand the pathogenic mechanisms underlying RVO in order to seek the best way to improve the long-term visual outcome.

\section{References}

1 The Central Vein Occlusion Study Group: Baseline and early natural history report. The Central Vein Occlusion Study. Arch Ophthalmol 1993;111:1087-1095.

2 Rogers S, McIntosh RL, Cheung N, Lim L, Wang JJ, Mitchell P, Kowalski JW, Nguyen H, Wong TY, International Eye Disease Consor- tium: The prevalence of retinal vein occlusion: pooled data from population studies from the United States, Europe, Asia, and Australia. Ophthalmology 2010;117:313-319.

3 Bandello F, Querques G (eds): Medical Retina. ESASO Course Series. Basel, Karger, 2012, vol 1.

\footnotetext{
4 Bressler NM, Schachat AP: Management of macular edema from retinal vein occlusions: you can never have too many choices. Ophthalmology 2010;117:1061-1063.

5 The Eye Disease Case-Control Study Group: Risk factors for central retinal vein occlusion. Arch Ophthalmol 1996;114:545-554.
} 
6 Rath EZ, Frank RN, Shin DH, Kim C: Risk $\$ 21$ Bynoe LA, Weiss JN: Retinal endovascular factors for central retinal vein occlusion: a case controlled study. Ophthalmology 1992; 99:509-514.

7 Hayreh SS, Zimmerman MB, Podhajsky P: Incidence of various types of retinal vein occlusion and their recurrence and demographic characteristics. Am J Ophthalmol 1994;117: 429-441.

8 Hayreh SS, Zimmerman MB, McCarthy MJ, 23 Podhajsky P: Systemic diseases associated with various types of retinal vein occlusion. Am J Ophthalmol 2001;131:61-77.

9 Green WR, Chan CC, Hutchins GM, Terry JM: Central vein occlusion: a prospective histological study of 29 eyes in 28 cases. Trans Am Ophthalmol Soc 1981;89:371-422.

10 Hayreh SS: Pathogenesis of occlusion of the central retinal vessels. Am J Ophthalmol 1971;72:998-1011.

11 The Central Vein Occlusion Study Group: Natural history and clinical management of central retinal vein occlusion. Arch Ophthalmol 1997;115:486-491.

-12 The Central Vein Occlusion Study Group: Evaluation of grid pattern photocoagulation for macular edema in central vein occlusion: the Central Vein Occlusion Study Group N report. Ophthalmology 1995;102:1434-1444.

$\checkmark 13$ Hattenbach LO, Steinkamp G, Scharrer I, et al: Fibrinolytic therapy with low-dose recombinant tissue plasminogen activator in retinal vein occlusion. Ophthalmologica 1998;212: 394-398.

14 Hattenbach LO, Wellermann G, Steinkamp $\mathrm{GW}$, et al: Visual outcome after treatment with low-dose recombinant tissue plasminogen activator or hemodilution in ischemic central retinal vein occlusion. Ophthalmologica 1999;213:360-366.

15 Lahey JM, Fong DS, Kearney J: Intravitreal tissue plasminogen activator for acute central retinal vein occlusion. Ophthalmic Surg Lasers 1999;30:427-434.

16 Glacet-Bernard A, Kuhn D, Vine AK, et al: Treatment of recent onset central retinal vein occlusion with intravitreal tissue plasminogen activator: a pilot study. $\mathrm{Br} \mathrm{J}$ Ophthalmol 2000;84:609-613.

17 Elman MJ, Raden RZ, Carrigan A: Intravitreal injection of tissue plasminogen activator for central retinal vein occlusion. Trans Am Ophthalmol Soc 2001;99:219-221, discussion pp 222-223.

18 Ghazi NG, Noureddine BN, Haddad RS, et al: Intravitreal tissue plasminogen activator in the management of central retinal vein occlusion. Retina 2003;23:780-784.

19 Weiss JN: Treatment of central retinal vein occlusion by injection of tissue plasminogen activator into a retinal vein. Am J Ophthalmol 1998; 126:142-144.

-20 Paques M, Vallee JN, Herbreteau D, et al: Superselective ophthalmic artery fibrinolytic therapy for the treatment of central retinal vein occlusion. Br J Ophthalmol 2000;84: 1387-1391. surgery and intravitreal triamcinolone acetone for central vein occlusion in young adults. Am J Ophthalmol 2003;135:382-384.

22 Gregori NZ, Rosenfeld PJ, Puliafito CA, et al: One-year safety and efficacy of intravitreal triamcinolone acetonide for the management of macular edema secondary to central retinal vein occlusion. Retina 2006;26:889-895

3 Scott IU, VanVeldhuisen PC, Oden NL, Ip MS, Blodi BA, Hartnett ME, Cohen G, SCORE Study Investigator Group: Baseline predictors of visual acuity and retinal thickness outcomes in patients with retinal vein occlusion. SCORE Study Report 10. Ophthalmology 2011;118:345-352.

-24 Ip MS, Scott IU, Van Veldhuisen PC, Oden NL, Bodi BA, Fisher M, Singerman LJ, Tolentino M, Chan CK, Gonzalez VH, SCORE Study Research Group: A randomized trial comparing the efficacy and safety of intravitreal triamcinolone with observation to treat vision loss associated with macular edema secondary to central retinal vein occlusion: the Standard Care vs Corticosteroid for Retinal Vein Occlusion (SCORE) study report 5. Arch Ophthalmol 2009;127:1101-1114.

25 Haller JA, Bandello F, Belfort R Jr, Blumenkranz MS, Gillies M, Heier J, et al: Randomized, sham-controlled trial of dexamethasone intravitreal implant in patients with macular edema due to retinal vein occlusion. Ophthalmology 2010;117:1134-1146.e3.

26 Haller JA, Bandello F, Belfort R Jr, Blumenkranz MS, Gillies M, Heier J, et al: Dexamethasone intravitreal implant in patients with macular edema related to branch or central retinal vein occlusion twelve-month study results. Ophthalmology 2011;118:2453-2460.

27 Rosenfeld PJ, Fung AE, Puliafito CA: Optical coherence tomography findings after an intravitreal injection of bevacizumab (Avastin) for macular edema from central retinal vein occlusion. Ophthalmic Surg Lasers Imaging 2005;36:336-339.

28 Iturralde D, Spaide RF, Meyerle CB: Intravitreal bevacizumab (Avastin) treatment of macular edema in central retinal vein occlusion: a short-term study. Retina 2006;26:279-284.

29 Wu L, Martínez-Castellanos MA, QuirozMercado H, Pan-American Collaborative Retina Group (PACORES): Twelve-month safety of intravitreal injections of bevacizumab (Avastin): results of the Pan-American Collaborative Retina Study Group (PACORES). Graefes Arch Clin Exp Ophthalmol 2008;246:81-87.

- 30 Brown DM, Campochiaro PA, Singh RP, Li Z, Gray S, Saroj N, Rundle AC, Rubio RG, Murahashi WY, CRUISE Investigators: Ranibizumab for macular edema following central retinal vein occlusion: six-month primary end point results of a phase III study. Ophthalmology 2010;117:1124-1133.e1.

-31 Campochiaro PA, Brown DM, Awh CC, Lee SY, Gra S, Saroj N, Murahashi WY, Rubio RG: Sustained benefits from ranibizumab for macular edema following central retinal vein occlusion: twelve-month outcomes of a phase III study. Ophthalmology 2011;118:20412049.

-32 Heier JS, Campochiaro PA, Yau L, Li Z, Saroj N, Rubio RG, Lai P: Ranibizumab for macular edema due to retinal vein occlusions: longterm follow-up in the HORIZON trial. Ophthalmology 2012;119:802-809.

33 Economides AN, Carpenter LR, Rudge JS, et al: Cytokine traps: multi-component, highaffinity blockers of cytokine action. Nat Med 2003;9:47-52.

34 Holash J, Davis S, Papadopoulos N, et al: VEGF-Trap: a VEGF blocker with potent antitumor effects. Proc Natl Acad Sci USA 2002; 99:11393-11398.

35 Stewart MW, Rosenfeld PJ: Predicted biological activity of intravitreal VEGF Trap. Br J Ophthalmol 2008;92:667-668.

36 Heier JS, Boyer D, Nguyen QD, et al, CLEARIT 2 Investigators: The 1-year results of CLEAR-IT 2, a phase 2 study of vascular endothelial growth factor Trap-Eye dosed as needed after 12-week fixed dosing. Ophthalmology 2011;118:1098-1106.

-37 Boyer D, Heier J, Brown DM, Clark WL, Vitti R, Berliner AJ, Groetzbach G, Zeitz O, Sandbrink R, Zhu X, Beckmann K, Haller JA: Vascular endothelial growth factor Trap-Eye for macular edema secondary to central retinal vein occlusion: six-month results of the phase 3 COPERNICUS study. Ophthalmology 2012;119:1024-1032.

38 Haller JA, Boyer DS, Heier JS, et al: VEGF Trap-Eye in CRVO: primary endpoint results of the phase 3 COPERNICUS study (abstract 6643). Paper presented at 2011 Annu Meet Assoc Res Vis Ophthalmol, Fort Lauderdale, May 3, 2011.

39 Wroblewski JJ, Wells JA, Adamis AP, Buggage RR, Cunningham ET Jr, Goldbaum M, Guyer DR, Katz B, Altaweel MM, Pegaptanib in Central Retinal Vein Occlusion Study Group: Pegaptanib sodium for macular edema secondary to central retinal vein occlusion. Arch Ophthalmol 2009;127:374-380.

40 Braithwaite T, Nanji AA, Greenbert PB: Antivascular endothelial growth factor for macular edema secondary to central retinal vein occlusion. Cochrane Database Syst Rev 2010; 6:CD007325.

41 Lam HD, Blumenkranz MS: Treatment of central retinal vein occlusion by vitrectomy with lysis of vitreopapillary and epipapillary adhesions, subretinalperipapillary tissue plasminogen activator injection, and photocoagulation. Am J Ophthalmol 2002;134:609-611.

42 Yeshaya A, Treister G: Pars plana vitrectomy for vitreous hemorrhage and retinal vein occlusion. Ann Ophthalmol 1983;15:615-617.

43 Furino C, Ferrari TM, Boscia F, Cardascia N: Combined radial optic neurotomy, internal limiting membrane peeling, and intravitreal triamcinolone acetonide for central retinal vein occlusion. Ophthalmic Surg Lasers Imaging 2005;36:422-425. 
44 Opremcak EM, Bruce RA, Lomeo MD, et al: Radial optic neurotomy for central retinal vein occlusion: a retrospective pilot study of 11 consecutive cases. Retina 2001;21:408415.

45 García-Arumí J, Boixadera A, Martinez-Castillo V, et al: Chorioretinal anastomosis after radial optic neurotomy for central retinal vein occlusion. Arch Ophthalmol 2003;121:13851391.

-46 García-Arumí J, Boixadera A, Martínez-Castillo $\mathrm{V}$, et al: Radial optic neurotomy in central retinal vein occlusion: comparison of outcome in younger vs older patients. Am J Ophthalmol 2007;143:134-140.

-47 Opremcak ME, Rehmar AJ, Ridenour CD, et al: Radial optic neurotomy for central retinal vein occlusion. Retina 2006;26:297-305.

48 Aggermann T, Brunner S, Krebs I, Haas P, Womastek I, Brannath W, et al: A prospective, randomised, multicenter trial for surgical treatment of central retinal vein occlusion: results of the Radial Optic Neurotomy for Central Vein Occlusion (ROVO) study group Graefes Arch Clin Exp Ophthalmol, E-pub ahead of print.

-49 Weinberg D, Dodwell DG, Fern SA: Anatomy of arteriovenous crossings in branch retinal vein occlusion. Am J Ophthalmol 1990;109: 298-302.

50 Zhao J, Sastry SM, Sperduto RD, Chew EY, Remaley NA: Arteriovenous crossing patterns in branch retinal vein occlusion. The Eye Disease Case-Control Study Group. Ophthalmology 1993;100:423-428.

-51 The Eye Disease Case-Control Study Group: Risk factors for branch retinal vein occlusion. Am J Ophthalmol 1993;116:286-296.

52 Wong TY, Larsen EK, Klein R, et al: Cardiovascular risk factors for retinal vein occlusion and arteriolar emboli: the Atherosclerosis Risk in Communities and Cardiovascular Health studies. Ophthalmology 2005;112: 540-547.

53 Frangieh GT, Green WR, Barraquer-Somers E, et al: Histopathologic study of nine branch retinal vein occlusions. Arch Ophthalmol 1982;100:1132-1140.

54 The Branch Vein Occlusion Study Group: Argon laser photocoagulation for macular edema in branch vein occlusion. Am J Ophthalmol 1984;98:271-282.

55 Murakami T, Takagi H, Kita M, Nishiwaki H, Miyamoto K, Ohashi H, Watanabe D, Yoshimura $\mathrm{N}$ : Intravitreal tissue plasminogen activator to treat macular edema associated with branch retinal vein occlusion. Am J Ophthalmol 2006;142:318-320.

56 García-Arumí J, Martinez-Castillo V, Boixadera A, Blasco H, Corcostegui B: Management of macular edema in branch retinal vein occlusion with sheathotomy and recombinant tissue plasminogen activator. Retina 2004;24:530-540.
57 Scott IU, Ip MS, VanVeldhuisen PC, Oden NL, Blodi BA, Fisher M, Chan CK, Gonzalez VH, Singerman LJ, Tolentino M, SCORE Study Research Group: A randomized trial comparing the efficacy and safety of intravitreal triamcinolone with standard care to treat vision loss associated with macular edema secondary to branch retinal vein occlusion: the Standard Care vs Corticosteroid for Retinal Vein Occlusion (SCORE) study report 6. Arch Ophthalmol 2009;127:1115-1128.

58 Kuppermann BD, Blumenkranz MS, Haller JA, et al, Dexamethasone DDS Phase II Study Group: Randomized controlled study of an intravitreous dexamethasone drug delivery system in patients with persistent macular edema. Arch Ophthalmol 2007;125:309-317.

-59 Yeh WS, Haller JA, Lanzetta P, Kuppermann BD, Wong TY, Mitchell P, et al: Effect of the duration of macular edema on clinical outcomes in retinal vein occlusion treated with dexamethasone intravitreal implant. Ophthalmology 2012;119:1190-1198.

60 Moisseiev E, Goldstein M, Waisbourd M, Barak A, Loewenstein A: Long-term evaluation of patients treated with dexamethasone intravitreal implant for macular edema due to retinal vein occlusion. Eye (Lond) 2013;27: 65-71.

61 Campochiaro PA, Hafiz G, Shah SM, et al: Ranibizumab for macular edema due to retinal vein occlusions: implication of VEGF as a critical stimulator. Mol Ther 2008;16:791799.

62 Yilmaz T, Cordero-Coma M: Use of bevacizumab for macular edema secondary to branch retinal vein occlusion: a systematic review. Graefes Arch Clin Exp Ophthalmol 2012;250:787-793.

63 Prager F, Michels S, Kriechbaum K, Georgopoulos M, Funk M, Geitzenauer W, Polak K, Schmidt-Erfurth U: Intravitreal bevacizumab (Avastin) for macular oedema secondary to retinal vein occlusion: 12 -month results of a prospective clinical trial. $\mathrm{Br} \mathrm{J}$ Ophthalmol 2009;93:452-456

64 Campochiaro PA, Heier JS, Feiner L, Gray S, Saroj N, Rundle AC, Murahashi WY, Rubio RG, BRAVO Investigators: Ranibizumab for macular edema following branch retinal vein occlusion: six-month primary end point results of a phase III study. Ophthalmology 2010;117:1102-1112.

65 Brown DM, Campochiaro PA, Bhisitkul RB, Ho AC, Gray S, Saroj N, et al: Sustained benefits from ranibizumab for macular edema following branch retinal vein occlusion: 12-month outcomes of a phase III study. Ophthalmology 2011;118:1594-1602.
66 Heier JS, Campochiaro PA, Yau L, Li Z, Saroj N, Rubio RG, et al: Ranibizumab for macular edema due to retinal vein occlusions: longterm follow-up in the HORIZON trial. Ophthalmology 2012;119:802-809.

67 Wroblewski JJ, Wells JA, Gonzales CR Pegaptanib sodium for macular edema secondary to branch retinal vein occlusion. Am J Ophthalmol 2010;149:147-154.

68 Takahashi M, Hikichi T, Akiba J, et al: Role of the vitreous and macular edema in branch retinal vein occlusion. Ophthalmic Surg Lasers 1997;28:294-299.

69 Stefansson E, Novack RL, Hatchell DL: Vitrectomy prevents retinal hypoxia in branch retinal vein occlusion. Invest Ophthalmol Vis Sci 1990;31:284-289.

70 Noma H, Funatsu H, Sakata K, Mimura T, Hori S: Macular microcirculation before and after vitrectomy for macular edema with branch retinal vein occlusion. Graefes Arch Clin Exp Ophthalmol 2010;248:443-445.

-71 Mester U, Dillinger P: Vitrectomy with arteriovenous decompression and internal limiting membrane dissection in branch retinal vein occlusion. Retina 2002;22:740-746.

72 Raszewska-Steglinska M, Gozdek P, Cisiecki S, Michalewska Z, Michalewski J, Nawrocki J: Pars plana vitrectomy with ILM peeling for macular edema secondary to retinal vein occlusion. Eur J Ophthalmol 2009;19:10551062.

-73 Arai M, Yamamoto S, Mitamura Y, Sato E, Sugawara T, Mizunoya S: Efficacy of vitrectomy and internal limiting membrane removal for macular edema associated with branch retinal vein occlusion. Ophthalmologica 2009;223:172-176.

-74 Osterloh MD, Charles S: Surgical decompression of branch retinal vein occlusions. Arch Ophthalmol 1988;106:1469-1471.

75 Kumar B, Yu DY, Morgan WH, et al: The distribution of angioarchitectural changes within the vicinity of the arteriovenous crossing in branch retinal vein occlusion. Ophthalmology 1998;105:424-427.

76 Muqit MM, Saidkasimova S, Keating D, Murdoch JR: Long-term study of vascular perfusion effects following arteriovenous sheathotomy for branch retinal vein occlusion. Acta Ophthalmol 2010;88:e57-e65.

77 Mason J 3rd, Feist R, White M Jr, Swanner J, McGwin G Jr, Emond T: Sheathotomy to decompress branch retinal vein occlusion: a matched control study. Ophthalmology 2004; 111:540-545.

78 Chung EJ, Lee H, Koh HJ: Arteriovenous crossing sheathotomy versus intravitreal triamcinolone acetonide injection for treatment of macular edema associated with branch retinal vein occlusion. Graefes Arch Clin Exp Ophthalmol 2008;246:967-974. 